University of Wollongong

Research Online

Faculty of Science, Medicine and Health -

Papers: Part B

Faculty of Science, Medicine and Health

$1-1-2019$

Scalable Solution Processing MoS2 Powders with Liquid Crystalline

Graphene Oxide for Flexible Freestanding Films with High Areal Lithium

Storage Capacity

Yunfeng Chao

University of Wollongong, yc682@uowmail.edu.au

Kezhong Wang

University of Wollongong, kw743@uowmail.edu.au

Rouhollah Jalili

University of Wollongong, rjalili@uow.edu.au

Alexander Morlando

University of Wollongong, am700@uowmail.edu.au

Chunyan Qin

University of Wollongong, cq287@uowmail.edu.au

See next page for additional authors

Follow this and additional works at: https://ro.uow.edu.au/smhpapers1

Publication Details Citation

Chao, Y., Wang, K., Jalili, R., Morlando, A., Qin, C., Vijayakumar, A., Wang, C., \& Wallace, G. G. (2019).

Scalable Solution Processing MoS2 Powders with Liquid Crystalline Graphene Oxide for Flexible

Freestanding Films with High Areal Lithium Storage Capacity. Faculty of Science, Medicine and Health -

Papers: Part B. Retrieved from https://ro.uow.edu.au/smhpapers1/1092

Research Online is the open access institutional repository for the University of Wollongong. For further information contact the UOW Library: research-pubs@uow.edu.au 


\title{
Scalable Solution Processing MoS2 Powders with Liquid Crystalline Graphene Oxide for Flexible Freestanding Films with High Areal Lithium Storage Capacity
}

\author{
Abstract \\ 2019 American Chemical Society. Freestanding flexible electrodes with high areal mass loading are \\ required for the development of flexible high-performance lithium-ion batteries (LIBs). Currently they face \\ the challenge of low mass loading due to the limited concentrations attainable in processable \\ dispersions. Here, we report a simple low-temperature hydrothermal route to fabricate flexible layered \\ molybdenum disulfide (MoS2)/reduced graphene oxide (MSG) films offering high areal capacity and good \\ lithium storage performance. This is achieved using a self-assembly process facilitated by the use of \\ liquid crystalline graphene oxide (LCGO) and commercial MoS2 powders at a low temperature of $70{ }^{\circ} \mathrm{C}$. \\ The amphiphilic properties of ultralarge LCGO nanosheets facilitates the processability of large-size \\ MoS2 powders, which is otherwise nondispersible in water. The resultant film with an areal mass of 8.2 \\ $\mathrm{mg} \mathrm{cm}-2$ delivers a high areal capacity of $5.80 \mathrm{mAh} \mathrm{cm}-2$ (706 mAh g-1) at $0.1 \mathrm{~A} \mathrm{~g}-1$. This simple method \\ can be adapted to similar nondispersible commercial battery materials for films fabrication or production \\ of more complicated constructs via advanced fabrication technologies.

\section{Publication Details} \\ Chao, Y., Wang, K., Jalili, R., Morlando, A., Qin, C., Vijayakumar, A., Wang, C. \& Wallace, G. (2019). Scalable \\ Solution Processing MoS2 Powders with Liquid Crystalline Graphene Oxide for Flexible Freestanding \\ Films with High Areal Lithium Storage Capacity. ACS Applied Materials and Interfaces,
}

\section{Authors}

Yunfeng Chao, Kezhong Wang, Rouhollah Jalili, Alexander Morlando, Chunyan Qin, Amruthalakshmi Vijayakumar, Caiyun Wang, and Gordon G. Wallace 


\title{
Scalable solution processing $\mathrm{MoS}_{2}$ powders with
}

\author{
liquid crystalline graphene oxide for flexible
}

\section{freestanding films with high areal lithium storage}

\section{capacity}

Yunfeng Chao ${ }^{1}$, Kezhong Wang ${ }^{1}$, Rouhollah Jalili ${ }^{2}$, Alexander Morlando ${ }^{3}$, Chunyan Qin ${ }^{1}$, Amruthalakshmi Vijayakumarl, Caiyun Wang ${ }^{l *}$, Gordon G. Wallace ${ }^{l *}$

1 ARC Centre of Excellence for Electromaterials Science, Intelligent Polymer Research Institute, AIIM Facility, University of Wollongong, North Wollongong, NSW 2500, Australia.

2 Particles and Catalysis Research Group, School of Chemical Engineering, The University of New South Wales, Sydney, New South Wales 2052, Australia

3 Institute for Superconducting and Electronic Materials, AIIM Facility, University of Wollongong, North Wollongong, NSW 2500, Australia.

Keywords: Liquid crystalline graphene oxide; $\mathrm{MoS}_{2}$ powders; flexible electrodes; high massloading; lithium-ion batteries. 
Abstract: Free-standing flexible electrodes with high areal mass-loading are required for the development of flexible high-performance lithium-ion batteries (LIBs). Currently they face the challenge of low mass loading due to the limited concentrations attainable in processable dispersions. Here, we report a simple low temperature hydrothermal route to fabricate flexible layered molybdenum disulfide $\left(\mathrm{MoS}_{2}\right)$ /reduced graphene oxide (MSG) films offering high areal capacity and good lithium storage performance. This is achieved using a self-assembly process facilitated by the use of liquid crystalline graphene oxide (LCGO) and commercial MoS2 powders at a low temperature of $70{ }^{\circ} \mathrm{C}$. The amphiphilic properties of ultra-large LCGO nanosheets facilitates the processability of large size $\mathrm{MoS}_{2}$ powders, which is otherwise non-dispersible in

water. The resultant film with an areal mass of $8.2 \mathrm{mg} \mathrm{cm}^{-2}$ delivers a high areal capacity of 5.80 $\mathrm{mAh} \mathrm{cm}^{-2}$ (706 mAh g-1) at $0.1 \mathrm{~A} \mathrm{~g}^{-1}$. This simple method can be adapted to similar nondispersible commercial battery materials for films fabrication or production of more complicated constructs via advanced fabrication technologies.

\section{Introduction}

Molybdenum disulfide $\left(\mathrm{MoS}_{2}\right)$ is commercially available and among the most industrially used semi-conducting transition metal dichalcogenide (TMD). Thanks to its layered S-Mo-S structure with an interlayer distance of $0.62 \mathrm{~nm},{ }^{1}$ it can support facile insertion/deinsertion of lithium ions with a theoretical capacity of $670 \mathrm{mAh} \mathrm{g}^{-1} .2,3$ This has placed $\mathrm{MoS}_{2}$ among the most promising anode materials for rechargeable and low cost lithium ion batteries (LIBs). However, the nondispersible nature of $\mathrm{MoS}_{2}$ powders means that they are not amendable to conventional solution processing. Therefore, they are commonly mixed with conductive additives, binders and polymers before deposition on a metal foil used for both mechanical support and as a current collector. The 
drawbacks with this approach are dead weight/volume of additives, inhomogeneous blending leading to power charge storage performance, high production cost and low durability due to delamination during charge-discharge cycling.

The ever-increasing demand for wearable and flexible devices requires robust, free-standing and flexible electrodes that can be easily manufactured into various shapes while avoiding excessive use of costly additives and metal substrates. ${ }^{4-6}$ Therefore, practical production of $\mathrm{MoS}_{2}-$ based freestanding electrodes for LIBs has become a major research focus. However, flexibility and performance of the state-of-art $\mathrm{MoS}_{2}$-based freestanding electrodes are still far from satisfactory. Freestanding $\mathrm{MoS}_{2}$-based electrode composites made of $\mathrm{MoS}_{2} / \mathrm{Ni}_{3} \mathrm{~S}_{2} / \mathrm{Ni}$ foam ${ }^{7}$, $\mathrm{MoS}_{2} /$ graphene foam ${ }^{8}$ and pressed $\mathrm{MoS}_{2} /$ nitrogen-doped graphene ${ }^{9}$ are mostly rigid and cannot tolerate deformation. The most flexible electrodes such as exfoliated $\mathrm{MoS}_{2} /$ graphene papers $(\sim 4$ $\left.\mathrm{mg} \mathrm{cm}{ }^{-2}\right)^{10}$ and our previously reported self-assembled exfoliated $\mathrm{MoS}_{2} /$ graphene structures $(\sim 1.5$ $\left.\mathrm{mg} \mathrm{cm}{ }^{-2}\right)^{11}$ still cannot achieve high areal mass electrode. This inherent limitation in $\mathrm{MoS}_{2}$ loading is due to limited concentrations attainable in processable dispersions. Therefore, the holy grail is integration of non-exfoliated $\mathrm{MoS}_{2}$ powder into freestanding electrodes to achieve a commercial acceptable level of areal mass $\left(\sim 10 \mathrm{mg} \mathrm{cm}^{-2}\right){ }^{12}$

This requires a versatile scaffolding material to assume the combination of appropriate mechanical and electrochemical properties. Aqueous dispersions of graphene derivatives including graphene oxide and graphene nanoplatelets are suitable for production of flexible and mechanically strong composites for battery applications. ${ }^{13,14}$ For instance, graphene oxide sheets with rich functional groups can interact with various nanomaterials to form stable dispersions enabling fabrication of freestanding films that include carbon nanotubes ${ }^{15,16}$, PPy nanoparticles ${ }^{17}$, 
$\mathrm{LiFeO}_{4}(50 \mathrm{~nm})$ and $\mathrm{Li}_{4} \mathrm{Ti}_{5} \mathrm{O}_{12}(<200 \mathrm{~nm})^{18}$. In these nanocomposites, graphene oxide sheets provide a stable porous network to support volume changes of the electrode during the charge/discharge cycles as well as to improve electrons transfer, thus achieving high cycle stability and good rate capability. ${ }^{19,20}$ However, accommodation of a high loading of micron size $\mathrm{MoS}_{2}$ particles in such structures has to date been challenging.

The use of liquid crystalline graphene oxide (LCGO) provides a combination of properties that enable the processing of composite materials from more concentrated dispersions. ${ }^{21}$ The amphiphilic property of LCGO supports formation of a nematic phase that can generate a selforganized structure comprising consecutive layers of active and scaffold materials. ${ }^{21}$ These robust hierarchical architectures have active material positioned between the ultra-large LCGO layers ${ }^{11,22}$. This stable reversibly expandable structure can be well preserved over the reduction process to attain high conductivity and electrochemical performance. ${ }^{23,24}$ These qualities are magnified once ultra-large and super flexible LCGO with exceptionally high aspect ratios (over 30, 000) is used..$^{25-}$ 27

Herein, we develop a practical and low temperature $\left(70{ }^{\circ} \mathrm{C}\right)$ hydrothermal route exploiting the self-assembly properties of ultra-large LCGO to process commercially sourced $\mathrm{MoS}_{2}$ powders to fabricate free-standing flexible $\mathrm{MoS}_{2} /$ reduced graphene oxide (MSG) films with an unrivaled high areal mass loading and performance. Commercial graphite electrodes have particle sizes in the order of tens micrometers (the size of STF44 from Timcal is $\sim 20 \mu \mathrm{m}$ ), so here similar large-size $\mathrm{MoS}_{2}$ powders $(<40 \mu \mathrm{m})$ are used here. ${ }^{28} \mathrm{MoS}_{2}$ powders and LCGO when dispersed together form a stable LC phase with $\mathrm{MoS}_{2}$ powders sandwiched between the giant LCGO sheets. Thus, a porous structure is created with interconnected channels inside the MSG film facilitating fast ion diffusion 
and enabling excellent electrochemical performance. The MSG film with a high mass loading of $8.2 \mathrm{mg} \mathrm{cm}^{-2}$ offers a high areal capacity of $5.80 \mathrm{mAh} \mathrm{cm}^{-2}\left(706 \mathrm{mAh} \mathrm{g}^{-1}\right)$ at $0.1 \mathrm{~A} \mathrm{~g}^{-1}$, much higher than today's commercial lithium-ion batteries $\left(2.5-3.5 \mathrm{mAh} \mathrm{cm}^{-2}\right)$ and majority of the previously reported $\mathrm{MoS}_{2}$ /graphene composites anodes (Table S1).

\section{Experimental}

\subsection{Preparation of LCGO dispersion}

LCGO dispersion was prepared using a modified Hummer's method ${ }^{29}$. Briefly, expandable graphite flakes (3772, Asbury Graphite Mills) were heated at $700{ }^{\circ} \mathrm{C}$ for $15 \mathrm{~s}$ to produce expanded graphite. Concentrated sulfuric acid $(400 \mathrm{~mL})$ was poured into expanded graphite $(2 \mathrm{~g})$ and kept stirring for $24 \mathrm{~h}$, followed by the addition of $\mathrm{KMnO}_{4}(15 \mathrm{~g})$ and stirring for another $24 \mathrm{~h}$. Ice bath was used to cool down the temperature during the slow adding of Milli-Q water (400 mL) into the mixture. Finally, $\mathrm{H}_{2} \mathrm{O}_{2}(30 \%, 100 \mathrm{ml})$ was added accompanying with a color change from black to light brown. Centrifugation method was used to rinse the LCGO dispersion, which included a three-time rinsing process with tenfold-diluted $\mathrm{HCl}$ solution $(4.2 \mathrm{wt} \%)$ to remove impurities, and then a rinsing process with Milli-Q water until its $\mathrm{pH}$ was above 5.

\subsection{Preparation of MSG films}

Commercial $\mathrm{MoS}_{2}$ particles (Alfa Aser, 325 mesh) with designated amount were added into LCGO dispersion ( $2 \mathrm{mg} \mathrm{ml}^{-1}, 10 \mathrm{ml}$ ) to get a homogeneous MSGO mixture using a vortex mixer. Then $\mathrm{H}_{3} \mathrm{PO}_{2}(50 \mathrm{wt} \%, 1 \mathrm{ml})$ was added as reduction agent and further mixed using vortex mixer. An $8 \mathrm{ml}$ of this mixed dispersion was transferred into a glass petri dish with a lid and heating in an oven of $70{ }^{\circ} \mathrm{C}$ for 6 hours at atmospheric pressure. The formed MSG hydrogels were rinsed 
with Milli-Q water and subjected to dialysis for several days until the $\mathrm{pH}$ close to 7 . Finally, a freeze-drying process was applied to fabricate free-standing MSG films. Pure rGO film without $\mathrm{MoS}_{2}$ powders was also produced as control. MSG films with high mass loading was fabricated through the same procedures but using high-concentration LCGO dispersions $\left(4,6\right.$ and $8 \mathrm{mg} \mathrm{ml}^{-}$ $\left.{ }^{1}\right)$ and the corresponding amount of $\mathrm{H}_{3} \mathrm{PO}_{2}(2,3$ and $4 \mathrm{ml})$.

\subsection{Material characterizations}

Cross-polarized optical microscope (Leica CTR 6000) operated in transmission mode was used to examine the birefringence of dispersions. Field emission scanning electron microscopy (FESEM, JEOL JSM-7500FA) was applied to investigate the nanostructure and morphology as well as collect energy dispersive spectroscopy (EDS) data for the elemental distribution. Mechanical properties of all films were conducted using a Shimadzu EZ mechanical tester at a cross-head speed of $1 \mathrm{~mm} \mathrm{~min}{ }^{-1}$. Four-point-probe equipment was used to measure the conductivity. Brunauer-Emmett-Teller (BET) tests were carried out by a Tristar II 3020 gas adsorption analyser (Micromeritics). Nitrogen gas $\left(\mathrm{N}_{2}\right)$ was used as adsorbate and measurements were run at liquid nitrogen temperature. Prior to measurement, samples were cut into small pieces to fit into the analysis tube and then degassed overnight at $110^{\circ} \mathrm{C}$. A hemispherical energy PHOIBOS 100/150 analyzer was used to collect the X-ray photoelectron spectroscopy (XPS) data. Raman spectra were obtained on a confocal Raman spectrometer (Jobin Yvon HR800, Horiba) using a 632.8nm diode laser. Thermogravimetric analysis (TGA) was conducted on a Pyris Diamond thermogravimetric/ differential thermal analyzer at a heating rate of $10{ }^{\circ} \mathrm{C} \mathrm{min}^{-1}$ in air flow.

\subsection{Electrochemical measurement}


All rGO and MSG films were pressed under a pressure of $10 \mathrm{MPa}$ for $30 \mathrm{~s}$ and cut into pieces of similar size $(0.8-1 \mathrm{~cm})$ before the use as working electrodes in 2032 coin cells coupled with lithium foils electrodes. These cells were assembled in an argon-filled glovebox (MBrau, UNIlab Plus). The electrolyte used was $1 \mathrm{M} \mathrm{LiPF}_{6}$ in a mixture of ethylene carbonate (EC) and dimethyl carbonate (DMC) (1:1, v/v; Aldrich). Neat $\mathrm{MoS}_{2}$ electrodes were prepared by coating a mixed slurry in N-Methyl-2-pyrrolidone (NMP) containing $\mathrm{MoS}_{2}$ particles, carbon black and polyvinylidene fluoride (PVDF) (weight ratio of 8:1:1) onto a copper foil, and then dried in a vacuum oven at $60{ }^{\circ} \mathrm{C}$ overnight. A Solartron SI 1287 electrochemical system was applied to record cyclic voltammograms $(\mathrm{CV})$ at a scan rate of $0.2 \mathrm{mV} \mathrm{s}^{-1}$ over a potential range of $0.01-3.0$ $\mathrm{V}\left(\right.$ vs. $\left.\mathrm{Li} / \mathrm{Li}^{+}\right)$. Galvanostatic charge/ discharge tests were conducted over a potential range of 0.005 $-3.0 \mathrm{~V}$ (vs. Li/ $/ \mathrm{Li}^{+}$) using a battery test system (Neware Electronic Co.). Specific capacity of rGO and all MSG films was calculated based on the mass of the composites. Gravimetric specific capacities were firstly calculated and then transferred into areal capacities using the areal mass of corresponding MSG films. Electrochemical impedance spectra (EIS) were acquired through a Biologic VSP electrochemical workstation over a frequency range of $100 \mathrm{kHz}$ to $0.01 \mathrm{~Hz}$ with an AC perturbation of $10 \mathrm{mV}$.

\section{Results and Discussion}

LCGO has proven to be a most useful graphene derivative when used for the fabrication of selfassembled dispersions and composites. LCGO has been employed as a dispersing agent to process carbon nanotubes and many other particles in water in order to produce hybrid self-organized composites. ${ }^{30}$ This is due to the amphiphilic properties of the ultra-large GO sheets, which makes them an ideal candidate as a water processing additive. Here, the LCGO dispersion was mixed and 
homogenized with various amount of commercial $\mathrm{MoS}_{2}$ powders to obtain homogeneous colloidal dispersions, which were then chemically reduced with $\mathrm{H}_{3} \mathrm{PO}_{2}$ over a simple hydrothermal thermal process at $70{ }^{\circ} \mathrm{C}$. Free-standing and flexible MSG films were obtained after freeze drying followed by pressing. In order to investigate the structural, mechanical and electrochemical properties of MSG, films of different weight ratios of $\operatorname{MoS}_{2}$ to $\operatorname{LCGO}(1: 1,2: 1$ and 4:1) as well as with different LCGO concentrations $\left(2,4,6\right.$ and $\left.8 \mathrm{mg} \mathrm{ml}^{-1}\right)$ were produced. For simplicity, samples and their dispersion precursors were respectively named as xMSGy and xMSGOy, in which $\mathrm{x}$ was the weight ratio between $\mathrm{MoS}_{2}$ and LCGO and y was the concentration of LCGO in precursors. For example, 2MSG6 film was made from a dispersion containing $6 \mathrm{mg} \mathrm{ml}^{-1} \mathrm{LCGO}$ and the mass ratio between $\mathrm{MoS}_{2}$ and LCGO was 2:1.

To investigate the anisotropic property of the MSGO dispersions, cross-polarized optical microscopy (POM) has been employed. Birefringence, characteristic of liquid crystals, can be easily recognized in the POM images collected under crossed-polarizers. ${ }^{21}$ Typically LCGO nanosheets orientated parallel to each other form robust LC domains due to the high aspect ratio and the resultant large excluded volume. ${ }^{26}$ The LCGO dispersion showed a clear anisotropy in its texture even after the addition of $\mathrm{MoS}_{2}$ (Figure 1a). After mixing with commercial $\mathrm{MoS}_{2}$ powders, POM images of all samples still maintained large areas of uniform orientation with random defects, confirming the presence of nematic LC order. The defects are attributed to some non-dispersed MoS2 particles on the surface, labelled by red arrows in Figure 1a and Figure S1.

The resulting $\mathrm{MoS}_{2}$ / LCGO dispersions were stable for several weeks without any observable graphene aggregation. Even though a small portion of the dispersed $\mathrm{MoS}_{2}$ settled down, gentle shaking was enough to redisperse the particles. The high aspect ratio of LCGO sheets along with 
the amphiphilic property are the main reason for the formation of this stable LC phase. ${ }^{11} \mathrm{MoS}_{2}$ particles are layered van der waals crystals, in which a plane of molybdenum atoms is sandwiched by planes of sulfide ions. Bulk $\mathrm{MoS}_{2}$ powder consists of stacked monolayers, which provide a very flat top surface that is ideal for the interaction with the LCGO sheets. The basal plane of LCGO sheets consists of many $\pi$-conjugated aromatic domains, which in solution can strongly interact with the flat surface of the $\mathrm{MoS}_{2}$ particles. Therefore, the electrostatic interaction between the $\mathrm{MoS}_{2}$ and LCGO enhances the stability of the dispersion and drives the $\mathrm{MoS}_{2}$ particles to be accommodated in the LC order. Interestingly, GO sheets at concentrations that do not form full LC (i.e. bi-phasic or isotropic) were not able to support and sustain the $\mathrm{MoS}_{2}$ dispersion in water (Figure 1b). For example, the 4MSGO mixture that was made from a mixture of $0.5 \mathrm{mg} \mathrm{ml}^{-1}$ LCGO dispersion resulted in the precipitation of metallic lustre $\mathrm{MoS}_{2}$ powders at the bottom of the vial (Figure 1b). LCGO at $0.5 \mathrm{mg} \mathrm{ml}^{-1}$ forms a bi-phasic LC phase comprise of GO mesogens that co-exist with water pockets - evidence for this bilayer formation. ${ }^{31}$ When the $\mathrm{MoS}_{2}$ particles are added to the bi-phasic LCGO, the particles do not intercalate between the GO sheets, thus stay non-soluble in water. On the other hand, when the concentration of LCGO dispersion reached 2 $\mathrm{mg} \mathrm{m}{ }^{-1}$ (full LC phase), $\mathrm{MoS}_{2}$ powders could be readily suspended while no precipitation was found even after standing for one week (Figure 1b). Furthermore, $\mathrm{MoS}_{2}$ particles precipitated quickly in a small-sized, non-LC GO dispersion even at relatively high concentration of $2 \mathrm{mg} \mathrm{ml}^{-}$ ${ }^{1}$ (Figure 1b). This result further indicates the role of a robust full LC phase to sustain the stability of MSGO dispersions in water.

A schematic representation of the process used in the production of stable MSGO dispersions and eventually MSG films is illustrated in Figure 1c. In our previous reported work ${ }^{32}$, results showed that giant LCGO nanosheets of hundreds micrometres aligned to produce LC domains, 
that self-organized into porous hydrogels as the rGO nanosheets produced through chemical reduction. In the MSGO dispersions, $\mathrm{MoS}_{2}$ powders were sandwiched between LCGO sheets and became wrapped in the porous skeletons of rGO nanosheets. Since $\mathrm{MoS}_{2}$ occupied the spaces between rGO nanosheets, a more compact structure was formed in the MSG film. Further increasing the concentration of MoS2 induced stronger interaction between $\mathrm{MoS}_{2}$ and LCGO, thus increasing the degree of order to produce more compact MSG films. The following SEM and Raman characterization techniques provide further evidence. 

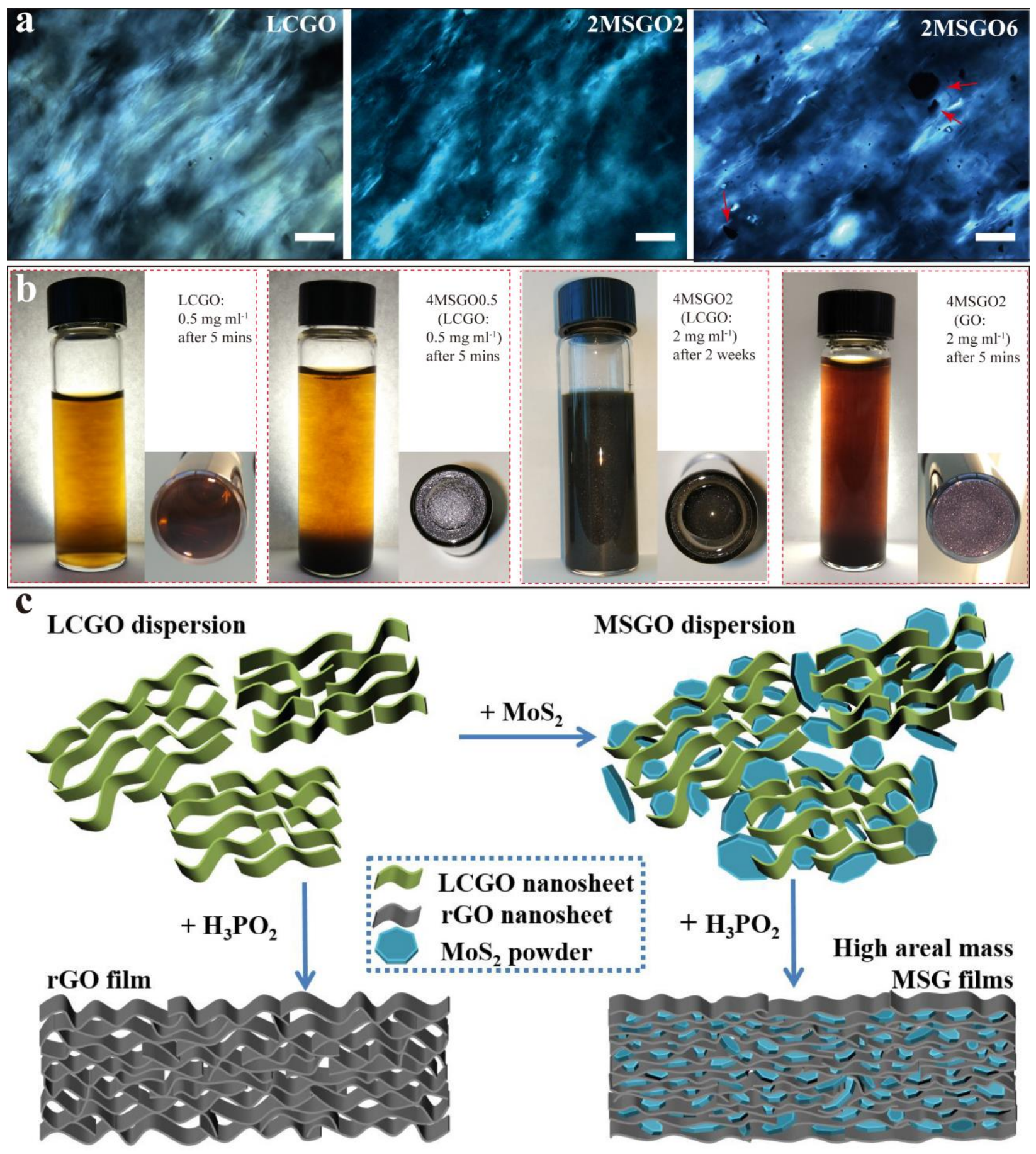

Figure 1 Properties of dispersion containing $\mathrm{MoS}_{2}$ and LCGO. (a) Cross-polarized optical microscope (POM) images of LCGO, 2MSGO2 and 2MSGO6 dispersions; (scale bars: $50 \mu \mathrm{m}$, defects were labelled by red arrows). (b) The stability of different 4MSGO mixtures; (c) Schematic illustration of the fabrication process of rGO and high areal mass MSG films. 
The shape and size of the rGO and MSG films are mainly determined by the mold used and the amount of dispersion. When the mold (glass petri dish in this work) had a diameter of $8.5 \mathrm{~cm}$, the diameter of produced MSG films was in a range of $4.3-4.6 \mathrm{~cm}$, slightly smaller than that of the rGO film $(5 \mathrm{~cm})$. This may be ascribed to the electrostatic interactions between $\mathrm{MoS}_{2}$ powders and LCGO nanosheets. ${ }^{33}$ MSG and rGO films all showed excellent flexibility when bent except for the 2MSG8 film with obvious cracks appearing (Figure 2a). We also fabricated large size 2MSGO6 film in a large petri dish $(17 \mathrm{~cm})$ using $2 \mathrm{MSGO6}$ with the same volumetric ratio to the mold as for small size film. The obtained MSG films displayed a larger diameter of $9.5 \mathrm{~cm}$ (Figure S2). These clearly demonstrate that the size and shape of produced films are mainly limited by the mold used for fabrication. MSG and rGO films all showed excellent flexibility when bent except for the 2MSG8 film with obvious cracks appearing (Figure 2a). rGO, 1MSG2, 2MSG2 and 4MSG2 films from dispersions containing the same amount of LCGO displayed similar thickness $(\sim 700 \mu \mathrm{m}$, Figure S3). The thickness of 2MSG4, 2MSG6 and 2MSG8 films apparently increased with the increase in LCGO content (Figure S3 b-h), further confirming the supporting role of the rGO backbone. Large size $\mathrm{MoS}_{2}$ powders could be easily recognized on the surface and in crosssectional SEM images of MSG films. They were all wrapped with wrinkled rGO nanosheets as marked by the red dash circles in Figure $2 \mathrm{c}$ and Figure $\mathrm{S} 3 \mathrm{j}$-o. The distribution of Mo and $\mathrm{S}$ elements in the EDS images of 2MSG6 film (Figure S4) also confirm the region of $\mathrm{MoS}_{2}$ particles.

Interconnected pores observed in the SEM images serve to increase the surface area and facilitate lithium ion transport producing high electrochemical performance. The use of increased LCGO concentrations resulted in decreased pore sizes in the 2MSG8 film, since at high concentrations the spacing between LCGO nanosheets became smaller resulting in the formation of small pores as depicted in Figure 2c. To investigate the porous structure of rGO and MSG films, Brunauer- 
Emmett-Teller (BET) tests were carried out and the collected nitrogen adsorption-desorption isotherms were shown in Figure S5 a-g. All samples showed type II/III isotherm indicative of macroporous materials. This result matched well with our SEM images, in which pores were as large as tens microns. The BET surface area was 92.1, 45.2, 52.7, 19.6, 38.9, 35.5 and $40.9 \mathrm{~m}^{2} \mathrm{~g}^{-1}$ for rGO, 1MSG2, 2MSG2, 4MSG2, 2MSG4, 2MSG6 and 2MSG8, respectively (Figure S5h). rGO film possessed the highest porosity, which decreased with the increased content $\mathrm{MoS}_{2}$ till the ratio between $\mathrm{MoS}_{2}$ and LCGO reached 4:1. It could be deduced that $\mathrm{MoS}_{2}$ had a negative effect on the porosity of MSG films. The increased LCGO concentration had little effect on the porosity of MSG films at the same $\mathrm{MoS}_{2} / \mathrm{LCGO}$ ratio of 2:1, as supported by no much difference shown in the BET surface area.

The rGO film displayed a low mass loading of $0.6 \mathrm{mg} \mathrm{cm}^{-2}$, and this increased to $1.7,2.6,4.3,5.2$ $\mathrm{mg} \mathrm{cm}^{-2}$ for $1 \mathrm{MSG} 2,2 \mathrm{MSG} 2,4 \mathrm{MSG} 2$ and 2MSG4 films, respectively. It even reached to $8.2 \mathrm{mg}$ $\mathrm{cm}^{-2}$ for 2MSG6 film and $11.1 \mathrm{mg} \mathrm{cm}^{-2}$ for 2MSG8 film (Figure 2d), close to or even higher than that of commercial electrodes $\left(\sim 10 \mathrm{mg} \mathrm{cm}^{-2}\right) \cdot{ }^{12}$ Such a high areal mass is attractive for achieving high areal capacity. Conductivity of rGO and MSG films was investigated using a four-point-probe technique (Figure 2d). The increased conductivity from $75 \mathrm{~S} \mathrm{~m}^{-1}$ for rGO film to $94 \mathrm{~S} \mathrm{~m}^{-1}$ for $1 \mathrm{MSG}$ and $231 \mathrm{~S} \mathrm{~m}^{-1}$ for $2 \mathrm{MSG}$ was attributed to the decreased porosity. $\mathrm{MoS}_{2}$ powders helped to bridge the neighbouring rGO nanosheets, accelerating the electron transfer between them. However, this effect reached its highest in 2MSG film while instinctive semi-conductive $\mathrm{MoS}_{2}$ powders resulted in the decreased conductivity in 4MSG film. Interestingly, the conductivity was constant in the composites with the same $\mathrm{MoS}_{2} / \mathrm{LCGO}$ ratios but increased precursor concentrations, confirming the key effect of $\mathrm{MoS}_{2} / \mathrm{LCGO}$ ratio on the conductivity. These properties were essential for obtaining good rate capability in the MSG films with high areal mass. 
The stress-strain profiles of rGO and MSG films were collected after pressing under $10 \mathrm{MPa}$ for 30s (Figure 2e). The thickness of rGO, 1MSG2, 2MSG2, 4MSG2, 2MSG4, 2MSG6 and 2MSG8 films was reduced to $124,72,85,97,108,173,243 \mu \mathrm{m}$, respectively. Compared to MSG films (2MSG2, 2MSG2 and 4MSG2) containing the same amount of GO, the higher thickness of pure rGO film displayed a higher thickness that should be attributed to the good structural elasticity enabled by its strong backbones. The increased content of $\mathrm{MoS}_{2}$ may facilitate the accommodation between the sheets resulting in lower thickness. The thickness of MSG films increased as the increase of precursor concentration. For the mechanical properties test, the fracture strength was 1.26, 2.64, 2.42 and 2.02 MPa for neat rGO, 1MSG2, 2MSG2 and 4MSG2 films, respectively; which was opposite to their thickness. Interestingly, the mechanical strength increased as the increase of LCGO concentration in the precursor dispersions; it was 2.42, 2.61, 2.73 and 2.84 $\mathrm{MPa}$ for 2MSG2, 2MSG4, 2MSG6 and 2MSG8 films, respectively. The increased concentration of LCGO precursors may be the main reason for the increments in both thickness and fracture strength. This result further emphasizes the key role of rGO nanosheets as robust supporting skeletons in the composite. 

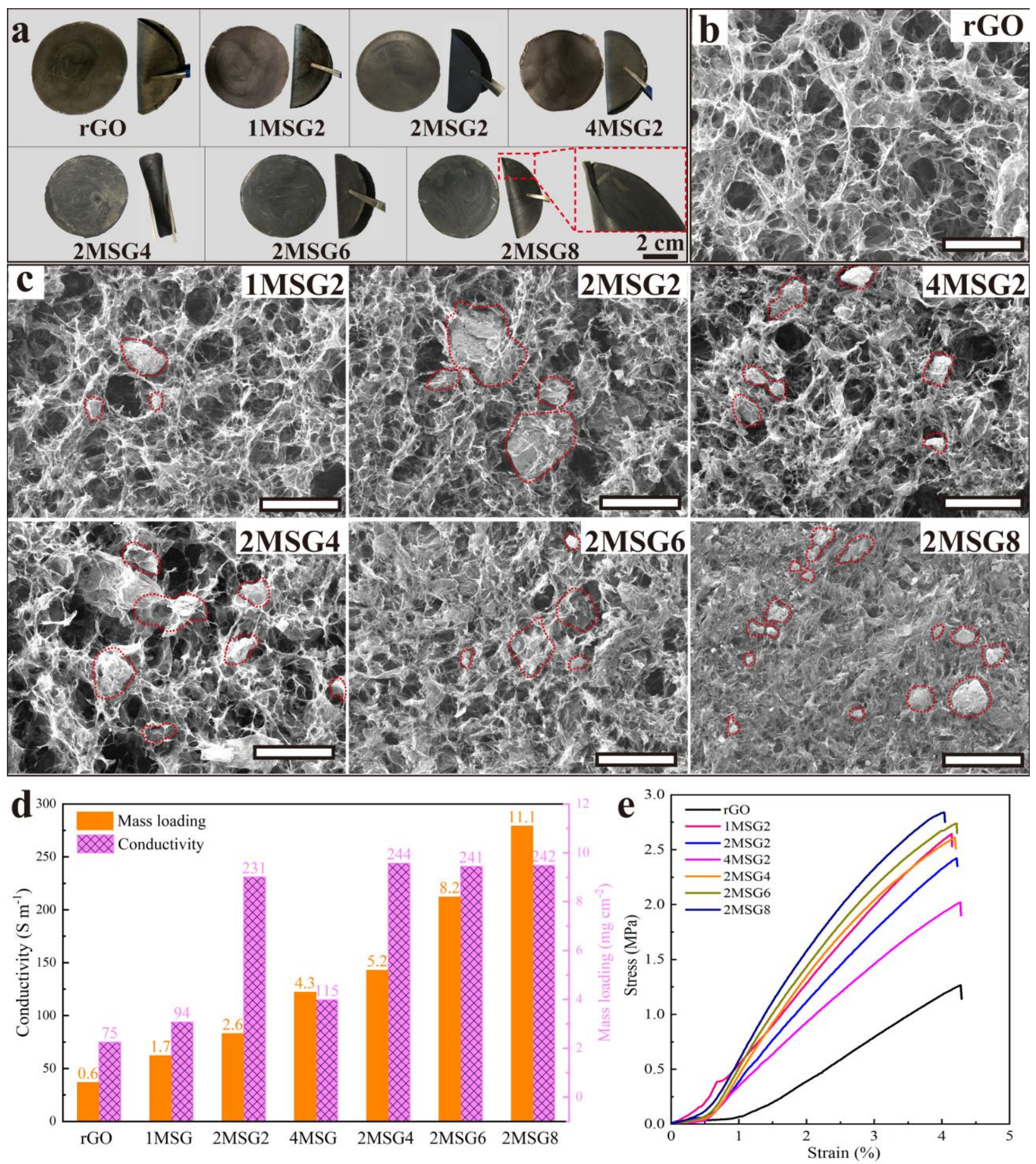

Figure 2 Morphology of MSG films. (a) Digital images of rGO and MSG films and the flexibility demonstration (Inset of 2MSG8 film shows the induced crack from the bending process); Surface morphologies (SEM images) of rGO (b) and MSG films (c), scale bar in (b, c): $100 \mu \mathrm{m} ;\left(\mathrm{MoS}_{2}\right.$ 
particles in MSG films were highlighted by red dash circles); (d) Areal mass and conductivity of rGO and MSG films; and (e) stress-strain curves of rGO and MSG films.

The XPS spectra of LCGO, rGO and all MSG films were collected to analyze the degree of reduction of LCGO nanosheets (Figure 3a, S6a). XPS C1s spectra were de-convoluted into three peaks around 284.2, 285.8 and $287.8 \mathrm{eV}$, which could be recognized as $\mathrm{sp}^{2}$ carbon or $\mathrm{sp}^{3}$ carbon $(\mathrm{C}-\mathrm{C} / \mathrm{C}=\mathrm{C}), \mathrm{C}-\mathrm{O}$ bond and $\mathrm{C}=\mathrm{O}$ bond, respectively. ${ }^{34,35}$ The intensity of $\mathrm{C}-\mathrm{O}$ peak and $\mathrm{C}=\mathrm{O}$ peak of all MSG films decreased dramatically compared to that of LCGO. The atomic ratio of carbon to oxygen $(\mathrm{C} / \mathrm{O})$ increased from 2.2 for LCGO to over 7.5 for all MSG films due to the removal of oxygen functional groups; also suggesting the successful reduction of GO. The $\mathrm{C} / \mathrm{O}$ ratios were 9.5, 8.5, 8.2 and 7.5 for 2MSG2, 2MSG4, 2MSG6 and 2MSG8, respectively. The descending C/O ratio with the ascending LCGO content indicates lower reduction efficiency for LCGO at high concentration. The peak ratio of $\mathrm{C}-\mathrm{C} / \mathrm{C}=\mathrm{C}$ bonds in the XPS $\mathrm{C} 1 \mathrm{~s}$ spectrum increased from $39 \%$ for LCGO to about $66 \%$ for rGO and MSG films, which implied that the aromatic domains at the basal plane of LCGO sheets were stable during the reduction process while the reducing oxygencontaining functional groups created more aromatic domains. XPS Mo3d spectra of commercial $\mathrm{MoS}_{2}$ powders and 2MSG6 film were also collected (Figure S6b). They all contained similar peaks including the Mo $3 \mathrm{~d} 3 / 2$ and Mo 3d5/2 peaks resulting from the $\mathrm{Mo}^{4+}$ in $\mathrm{MoS}_{2}$, and the $\mathrm{Mo}^{6+}-\mathrm{O}$ peak that was assigned to the partially oxidized Mo atoms on the sample surface. This result demonstrated the stability of $\mathrm{MoS}_{2}$ during the reduction process.

Distinct peaks at $374.5,406.6$, and $455.7 \mathrm{~cm}^{-1}$ were observed in the Raman spectra of $\mathrm{MoS}_{2}$ powder and all MSG films (Figure 3b, S6d), which respectively correspond to the $\mathrm{E}_{2 \mathrm{~g}}{ }_{2}, \mathrm{~A}_{1 \mathrm{~g}}$, and 2LA modes of hexagonal $\mathrm{MoS}_{2}$ crystal. ${ }^{6,36} \mathrm{Neat}$ rGO and all MSG films showed two typical carbon 
peaks representing the co-existence of $\mathrm{sp}^{3}$ disordered carbon (D band at $1330 \mathrm{~cm}^{-1}$ ), and $\mathrm{sp}^{2} 2 \mathrm{D}$ graphite carbon (G band at $\left.1587 \mathrm{~cm}^{-1}\right){ }^{37}$ The intensity ratio of $\mathrm{D}$ band to $\mathrm{G}$ band $\left(\mathrm{I}_{\mathrm{d}} / \mathrm{I}_{\mathrm{g}}\right)$ was 2.34 for rGO film. It gradually deceased with the increased areal mass of MSG films to 2.33, 2.27, 2.2, 2.15, 2.1 and 2 for 1MSG2, 2MSG2, 4MSG2, 2MSG4, 2MSG6 and 2MSG8 films, respectively. The increased precursor concentrations as well as the interactions between LCGO and $\mathrm{MoS}_{2}$ powders may confine the wrinkling and folding of reduced LCGO. Thus ordered level of rGO nanosheets and in-plane $\mathrm{sp}^{2}$ domains were increased, which should be the reason for the descending $\mathrm{I}_{\mathrm{d}} / \mathrm{I}_{\mathrm{g}}$ for MSG films.

XRD data were recorded to further examine the chemical structure of rGO and MSG films (Figure S6b). rGO and all MSG films displayed a peak around $26^{\circ}$, revealing the 002 planes of reduced graphene oxide. ${ }^{38}$ All MSG films and $\mathrm{MoS}_{2}$ powders displayed a diffraction peak at $14.5^{\circ}$, which can be described as the (002) plane of $2 \mathrm{H}-\mathrm{MoS}_{2}$ (JCPDS 37-1492).${ }^{39}$ Thermal stability of $\mathrm{MoS}_{2}$ powders, rGO and all MSG films was investigated by thermal gravimetric analysis (TGA) in air gas flow (Figure 3d). The slight weight loss from $120{ }^{\circ} \mathrm{C}$ to $500{ }^{\circ} \mathrm{C}$ for rGO film was caused by the removal of moisture and residual functional oxygen-containing groups, and a steep weight loss after $530{ }^{\circ} \mathrm{C}$ can be ascribed to the oxidation of rGO to $\mathrm{CO}_{2} \cdot{ }^{40}$ It was completely decomposed at $650{ }^{\circ} \mathrm{C}$. The weight loss for neat $\mathrm{MoS}_{2}$ powders beyond $460{ }^{\circ} \mathrm{C}$ should be attributed to the decomposition of $\mathrm{MoS}_{2}$ to $\mathrm{MoO}_{3}{ }^{41}$ For MSG films, their $\mathrm{MoS}_{2}$ contents could be calculated as $65.5 \%, 79.9 \%, 88 \%, 78.9 \%, 78.5 \%$ and $75.1 \%$ for $1 \mathrm{MSG} 2,2 \mathrm{MSG} 2,4 \mathrm{MSG} 2,2 \mathrm{MSG} 4,2 \mathrm{MSG} 6$ and 2MSG8 films, respectively. These values matched well with their initial amount in the precursors. The areal mass of $\mathrm{MoS}_{2}$ in 2MSG2, 2MSG4, 2MSG6 and 2MSG8 films displayed a decreasing tendency, which was resulted from the decreased reducing rate as illustrated by their C/O ratios from XPS tests. 

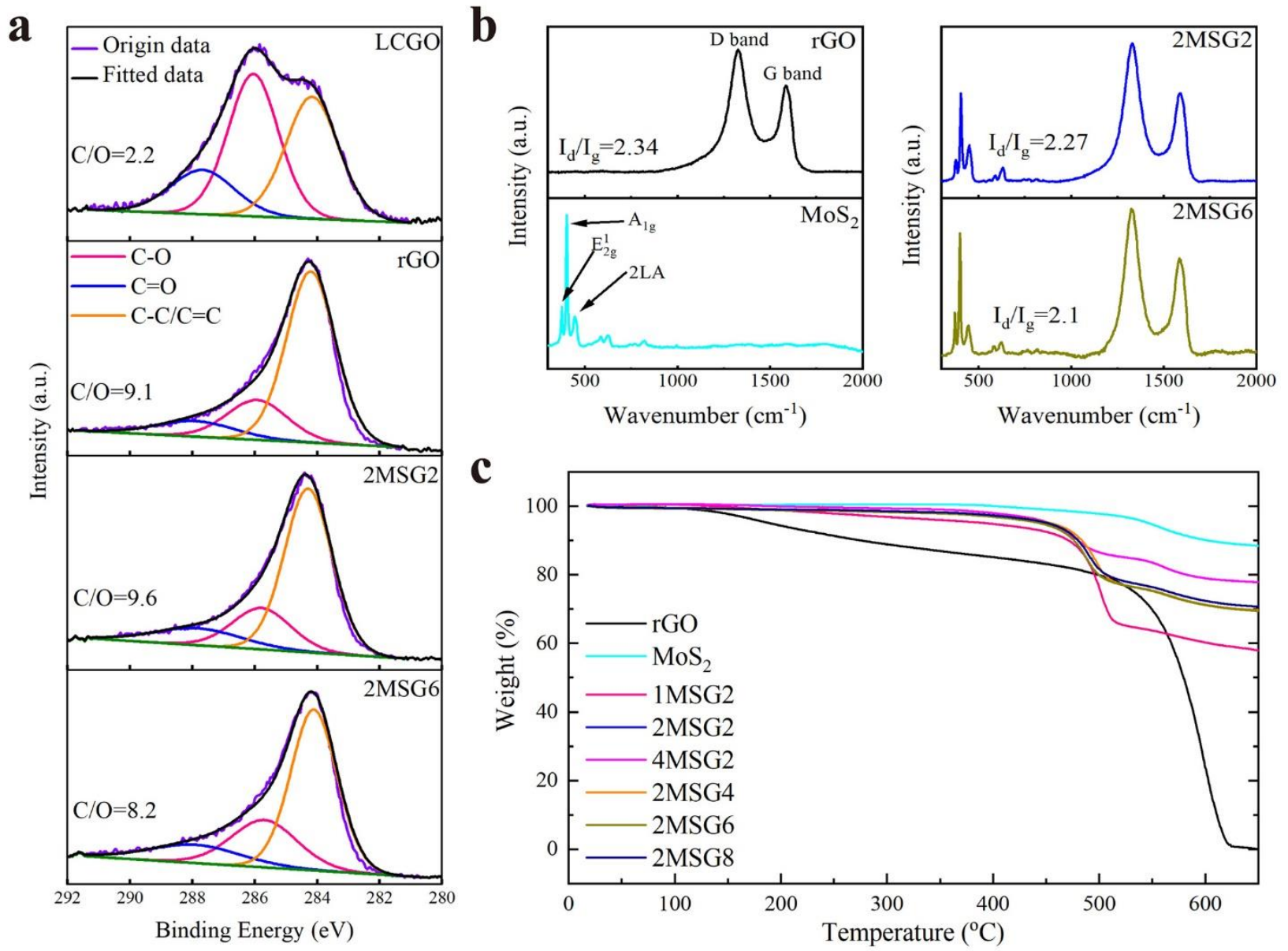

Figure 3 Chemical states and thermal stability of $\mathrm{MoS}_{2}$, rGO and MSG films. (a) XPS C1s spectra of LCGO, rGO, 2MSG and 2MSG6 films; Raman spectra (b) and TGA curves (c) of MoS2, rGO, 2MSG and 2MSG6 films.

Cyclic voltammograms (CV) of rGO, MoS 2 and MSG films are shown in Figure 4 a-b and S7a. $\mathrm{MoS}_{2}$ and MSG electrodes all displayed two main peaks in the first cathodic scan. The peak at 0.9 $\mathrm{V}$ was ascribed to the insertion of lithium ions into $\mathrm{MoS}_{2}$ forming $\mathrm{Li}_{\mathrm{x}} \mathrm{MoS}_{2}{ }^{42}$ The peak at $0.42 \mathrm{~V}$ was resulted from the reduction of $\mathrm{Li}_{x} \mathrm{MoS}_{2}$ to $\mathrm{Mo}$ and $\mathrm{Li}_{2} \mathrm{~S}$, as well as the formation of a solid electrolyte interface (SEI) layer. ${ }^{42,43}$ The depletion of $\mathrm{MoS}_{2}$ during this process is irreversible, but the SEI formation continued in the consecutive several cycles. This explains the presence of a 
much weak peak at $0.42 \mathrm{~V}$ in the following two cycles. ${ }^{44,45} \mathrm{In}$ the anodic scan the major peak at $\sim 2.4 \mathrm{~V}$ could be recognized as the delithiation process of $\mathrm{Li}_{2} \mathrm{~S}_{\text {to }} \mathrm{Li}^{+}$and $\mathrm{S} .{ }^{11} \mathrm{MoS}_{2}$ was completely transferred into $\mathrm{Mo}$ and $\mathrm{S}$ in the first cycle and cannot restore to $\mathrm{MoS}_{2}$ anymore. Two new reduction peaks at $1.8 \mathrm{~V}$ and $1.1 \mathrm{~V}$ in the following scans can be attributed to the association of lithium ions with S and Mo, respectively. ${ }^{46}$ The first three discharge-charge profiles of $2 \mathrm{MSG} 2$ and 2MSG6 are shown in Figure $4 \mathbf{c}$-d, while those for rGO, $\mathrm{MoS}_{2}$ and other MSG films are shown in Figure S7b. All plateaus in the discharge and charge curves are in good accordance with their peaks in CV. rGO film displayed an initial coulombic efficiency (CE) of 53\%, attributed to the formation of significant amount of SEI on its large surface area and trapping of lithium ions in the defect-rich structure. ${ }^{47,48}$ The high initial CE of $83 \%$ from neat $\mathrm{MoS}_{2}$ is mainly due to its compact structure with small surface area for the formation of SEI ${ }^{49}$ With the decreased structural porosity from the increased total concentration of precursors, the initial CE increased to $85 \%$ for 2MSG film and $78 \%$ for $2 \mathrm{MSG} 6$ film, higher than that of many reported $\mathrm{MoS}_{2} /$ graphene composites. ${ }^{9,50,51}$

Rate capability (Figure 4e, Figure S7c), EIS and cycling stability of freestanding rGO and MSG films were all investigated for comparison. Since the neat $\mathrm{MoS}_{2}$ electrode on a copper foil substrate was not flexible yet with much lower areal mass-loading $\left(\sim 1.5 \mathrm{mg} \mathrm{cm}^{-2}\right)$, it was not feasible to make reasonable comparison, thus its performance was not included in this work to avoid misinterpretation. Neat rGO film displayed a capacity of $475 \mathrm{mAh} \mathrm{g}^{-1}\left(0.28 \mathrm{mAh} \mathrm{cm}^{-2}\right)$ at $0.1 \mathrm{~A} \mathrm{~g}^{-}$ ${ }^{1}$ (5th cycle). After the addition of $\mathrm{MoS}_{2}$ powders, the capacities were dramatically increased to 716, 752 and $759 \mathrm{mAh} \mathrm{g}^{-1}$ (i.e., 1.22, 1.96, $3.26 \mathrm{mAh} \mathrm{cm}^{-2}$ ) for 1MSG2, 2MSG2 and 4MSG films, respectively. MSG films with higher areal mass offered high gravimetric capacity as well. 2MSG4, 2MSG6 and 2MSG8 films delivered a capacity of 735, 707 and $695 \mathrm{mAh} \mathrm{g}^{-1}(3.82,5.80,7.71 \mathrm{mAh}$ 
$\mathrm{cm}^{-2}$ ), respectively. The areal capacity of 2MSG6 film was higher than the reported folded $\mathrm{SnO}_{2}$ /graphene film $\left(4.15 \mathrm{mAh} \mathrm{cm}^{-2}\right)^{52}$, typical commercial electrodes $\left(2.5-3.5 \mathrm{mAh} \mathrm{cm}^{-2}\right)^{52}$ and most $\mathrm{MoS}_{2}$ /graphene composites (Table S1). 2MSG6 film displayed a high areal capacity of 0.98 $\mathrm{mAh} \mathrm{cm}$ at a high current density of $1 \mathrm{~A} \mathrm{~g}^{-1}\left(8.2 \mathrm{~mA} \mathrm{~cm}^{-2}\right)$, which is about two times than that of 2MSG2 film (0.52 $\mathrm{mAh} \mathrm{cm}^{-2}$ at $\left.1 \mathrm{~A} \mathrm{~g}^{-1}\right)$.

Nyquist plots of $\mathrm{rGO}, \mathrm{MoS}_{2}$ and $\mathrm{MSG}$ films were collected after the rate capability tests and fitted using equivalent circuit (Figure 4f, S7d). In the Nyquist plot, the line slop at low frequency is positively correlated with the ion diffusion rate. The semicircle in medium frequency is related to charge transfer resistance $\left(\mathrm{R}_{\mathrm{ct}}\right)$ while intercept at high frequency corresponds to bulk resistance including solution and contact resistance $\left(\mathrm{R}_{\mathrm{s}}\right)$. CPE and $\mathrm{W}_{\mathrm{o}}$ used in the equivalent circuit represent constant phase element and Warburg impedance, respectively. The $\mathrm{R}_{\mathrm{ct}}$ value of rGO was $175 \Omega$, slightly lower than that of all MSG films $(\sim 200 \Omega)$. This confirms that rGO was the main conductive materials in MSG composites and provided a similar electron transfer rate along the rGO networks. The line slope at low frequency decreased with the areal mass of composites, indicating a deteriorative ions transportation resulted from the compact structure. This is well matched with the poor rate performance from high areal-mass MSG films. 

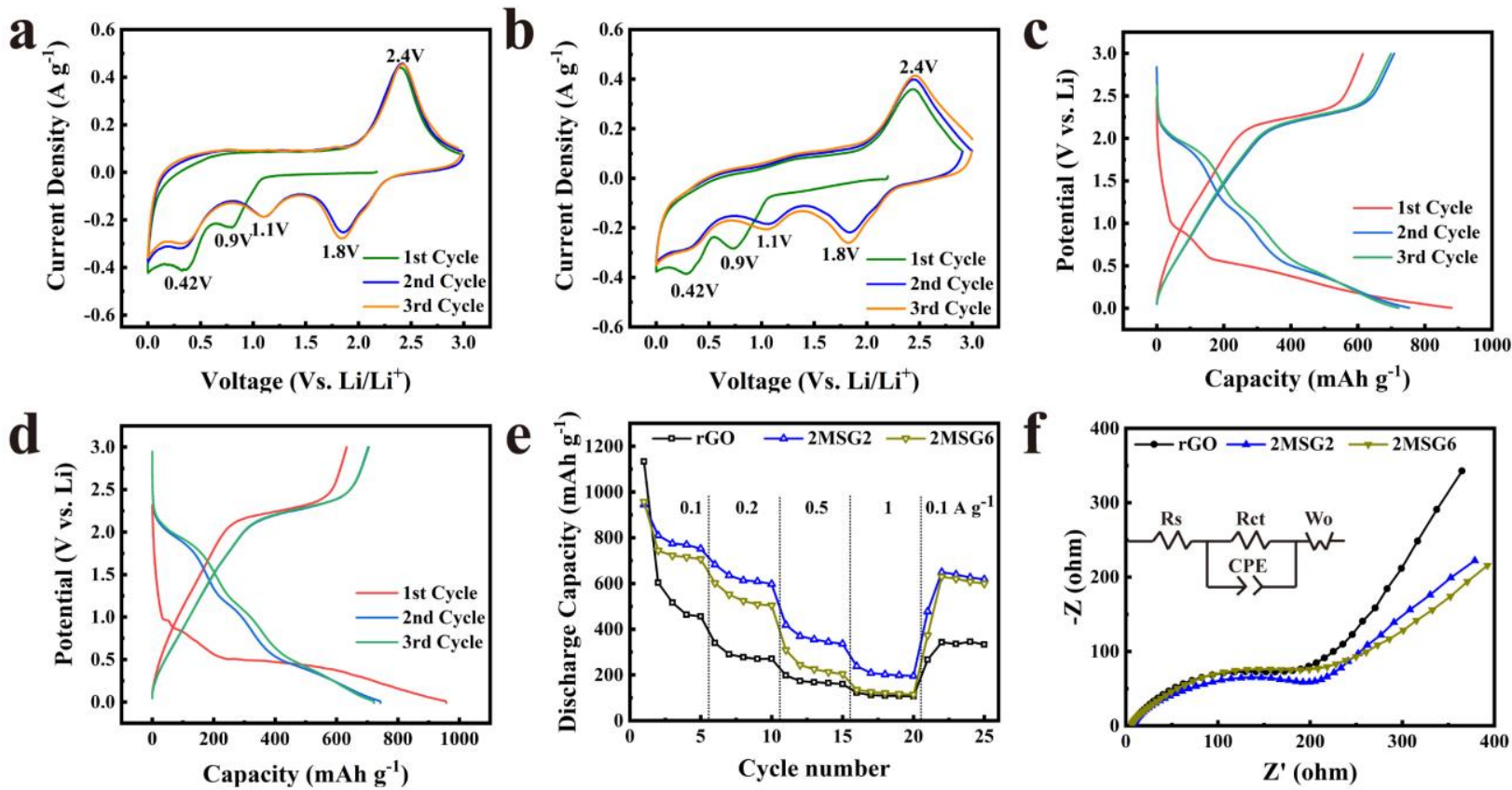

Figure 4 Electrochemical performance of MSG films. Cyclic voltammograms of 2MSG film (a) and 2MSG6 film (b) at a scan rate of $0.2 \mathrm{mV} \mathrm{s}^{-1}$; The first three discharge/charge profiles of 2MSG film (c) and 2MSG6 film (d) at a current density of $0.1 \mathrm{~A} \mathrm{~g}^{-1}$; (e) Rate capabilities of rGO, neat $\mathrm{MoS}_{2}, 2 \mathrm{MSG}$ and 2MSG6 films; (f) Nyquist plots of rGO, $\mathrm{MoS}_{2}, 2 \mathrm{MSG}$ and 2MSG6 films over a frequency range of $100 \mathrm{kHz}$ to $10 \mathrm{mHz}$ (Inset: equivalent circuit).

Cycling stability was tested after rate capability tests at a current density of $0.1 \mathrm{~A} \mathrm{~g}^{-1}$ for 200 cycles (Figure 5a). Neat rGO film showed a much stable capacity during the whole cycling test with $88 \%$ of its initial capacity retained. $1 \mathrm{MSG} 2$ and 2MSG2 films displayed a small capacity dropping during the initial 60 cycles, then it gradually increased to 617 and $511 \mathrm{mAh} \mathrm{g}^{-1}$ at the $200^{\text {th }}$ cycle, $91 \%$ and $79 \%$ of the initial capacity, respectively. The capacity degradation at the initial stage may be due to the volume changes of $\mathrm{MoS}_{2}$ powders and formation of SEI. The following capacity increasing may be mainly due to the porous structure which may provide pathways to progressively access those embedded $\mathrm{MoS}_{2}$ powders. 2MSG4 and 2MSG6 films with 
higher $\mathrm{MoS}_{2}$ content all maintained $~ 55 \%$ of their capacity after 200 cycles, and only 35\% was retained for 4MSG2 and 2MSG8 films. These results clearly demonstrate that the films with high $\mathrm{MoS}_{2}$ content faced serve capacity fading problems, which may be ascribed to volume changes of $\mathrm{MoS}_{2}$. Taking areal capacity into consideration, 2MSG6 with a mass loading of $8.2 \mathrm{mg} \mathrm{cm}^{-2}$ delivered the highest areal capacity of $2.80 \mathrm{mAh} \mathrm{cm}^{-2}$ after 200 cycles, much higher than all other MSG films. It was also still comparable with previously reported $\mathrm{MoS}_{2}$ /graphene-based composite (Table S1) and commercial electrodes $\left(2.5-3.5 \mathrm{mAh} \mathrm{cm}^{-2}\right) .{ }^{12}$

All electrodes were examined after the cycling tests (Figure $5 \mathbf{b}$ b-c). The rGO film kept an intact surface without any cracks, confirming that the stable structure was responsible for its stable cycling stability. 1MSG2 and 2MSG2 films were basically still in an integrated form but with tiny cracks. It may be explained by that the strong rGO skeleton in the composite tolerated the volume expansion of $\mathrm{MoS}_{2}$. For 2MSG4 and 2MSG6 films, small cracks appeared on the surface, evidencing the occurring of structure failures that may trap active materials in isolating sites and lose lithium inventory in fresh-formed solid-electrolyte interphase layer. ${ }^{53}$ 4MSG2 and 2MSG8 films with high $\mathrm{MoS}_{2}$ content presented even worse structural failure, as evidenced by the presence of large cracks on the surface. All these results confirmed that the robust rGO skeleton and porous structure could confine the volume changes of $\mathrm{MoS}_{2}$, highlighting the importance of a stable structure to the cycling stability.

The optimized ratio between $\mathrm{MoS}_{2}$ and LCGO was found to be 2:1 (MoS $/$ LCGO) for 2MSG6 giving the highest robustness and electrochemical performance. The 2MSG6 showed the highest areal mass of $8.2 \mathrm{mg} \mathrm{cm}^{-2}$ and consequently the highest areal capacity of $5.8 \mathrm{mAh} \mathrm{cm}{ }^{-2}$ at $0.1 \mathrm{~mA}$ $\mathrm{g}^{-1}$. On top, 2MSG6 performed well over the flexibility and durability tests. The addition of this 
optimum amount of $\mathrm{MoS}_{2}$ provided high capacity for 2MSG6 film while the rGO skeletons ensured robustness, flexible and porous structure. This structure can provide an express electron transfer network for good rate capability, high surface area for the loading of more electrolyte ions and accelerated ion diffusion rate. The excellent mechanical properties enabled stable performance during cycling. Moreover, those unique properties may expand the application of MSG films in other batteries such as sodium ion batteries or as catalysts for the hydrogen evolution reaction. ${ }^{54}$

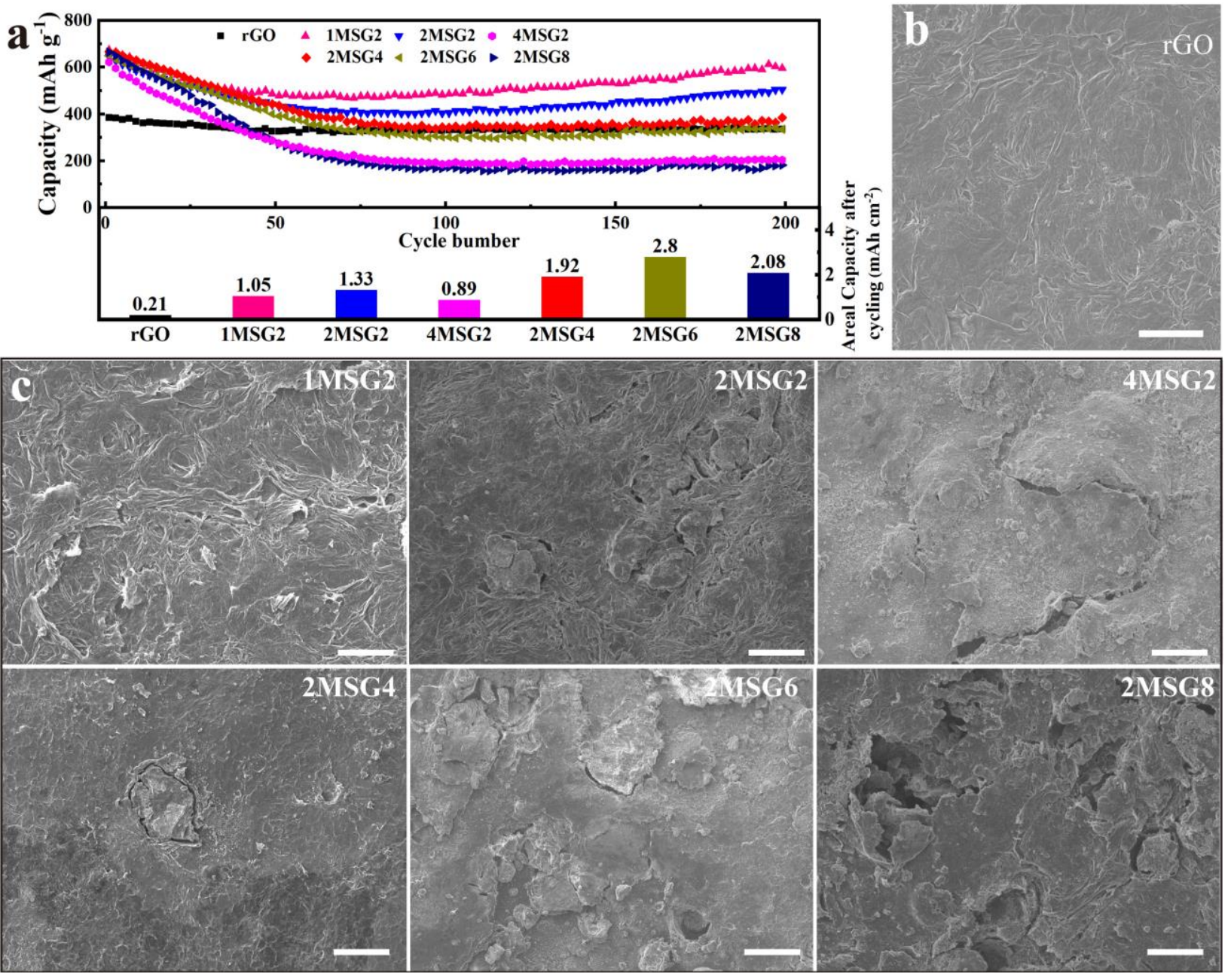


Figure 5 Cycling stability of MSG films. (a) Cycling stability and areal capacity after cycling of rGO and all MSG films at a current density of $100 \mathrm{~mA} \mathrm{~g}^{-1}$; Surface SEM images of rGO (b) and MSG films (c) after cycling tests (Scale bar: $25 \mu \mathrm{m}$ ).

\section{Conclusion}

In this work, we develop a simple method to fabricate freestanding flexible $\mathrm{MoS}_{2} / \mathrm{reduced}$ graphene oxide (MSG) films directly from low-cost commercial $\mathrm{MoS}_{2}$ powders by using liquid crystalline graphene oxide (LCGO) to confine these large particles forming stable dispersion. The LC orders in LCGO are robust to hold high content of large-size $\mathrm{MoS}_{2}$ powders while preserving the LC state. MSG films with a porous sandwiched structure display good electrochemical performance as anodes in lithium-ion batteries, as the porous structure accommodate the volume change of $\mathrm{MoS}_{2}$ powders and provide easy access of electrolyte. The 2MSG6 film with 78.5\% $\mathrm{MoS}_{2}$ can offer a high areal capacity of $2.8 \mathrm{mAh} \mathrm{cm}{ }^{-2}$ even after 200 cycles at $0.1 \mathrm{~A} \mathrm{~g}^{-1}(0.82 \mathrm{~mA}$ $\mathrm{cm}^{-2}$ ). This type of freestanding electrodes directly fabricated from low-cost commercial $\mathrm{MoS}_{2}$ powders with high areal mass and good electrochemical performance are attractive for practical applications. This work also demonstrates the feasibility of solution processing undispersable and large-size materials by using LCGO dispersion.

\section{Supporting information}

The Supporting Information is available free of charge on the ACS Publications website.

Cross-polarized optical microscope (POM) images of 1MSGO2, 4MSGO2, 2MSGO4 and 2MSGO8 dispersions; A snapshot of 2MSG6 film (diameter: $9.5 \mathrm{~cm}$ ) obtained in a large petri dish; SEM of $\mathrm{MoS}_{2}$ powders; Cross-sectional SEM images of rGO film and MSG films; High 
magnification cross-sectional SEM images of rGO film and MSG films; EDS mapping images of C, Mo and S elements for 2MSG6 film; Nitrogen adsorption-desorption isotherms and BET surface area of rGO and MSG films; XPS C1s, XRD and Raman spectra of 1MSG2, 4MSG2, 2MSG4 and 2MSG8 films; XPS Mo3d spectra of $\mathrm{MoS}_{2}$ and 2MSG6; Cyclic voltammograms and the first three discharge/charge curves of rGO, MoS2, 1MSG2, 4MSG2, 2MSG4 and 2MSG8 films; Rate capabilities of 1MSG2, 4MSG2, 2MSG4 and 2MSG8 films; Nyquist plots of 1MSG2, 4MSG2, 2MSG4 and 2MSG8 films over a frequency range of $100 \mathrm{kHz}$ to $10 \mathrm{mHz}$; Cycling performance of some representative $\mathrm{MoS}_{2}$ based composites in half coin cells with lithium foils as counter electrodes.

\section{AUTHOR INFORMATION}

\section{Corresponding author}

*Dr. Caiyun Wang

Intelligent Polymer Research Institute, ARC Centre of Excellence for Electromaterials Science, AIIM Facility, Innovation Campus, University of Wollongong, Wollongong, NSW 2522 Australia. Tel: +61 2 42981426. Fax: +61 24298 1499. E-mail: caiyun@uow.edu.au (C.W.).

\section{Author contributions}

The manuscript was written through contributions of all authors. All authors have given approval to the final version of the manuscript. Y. Chao, C. Wang, R. Jalili and G. Wallace conceived the idea of this manuscript, designed the experiment and wrote manuscript. C. Qin collected the Raman data of the MSG composites. Y. Chao and K. Wang synthesized the LCGO dispersion 
together. A. Morlando did the BET tests and helped to analyse the data. A. Vijayakumar characterization the MSG films using XRD. G. Wallace and C. Wang supervised the study.

\section{Funding sources}

The project was funded by the Australian Research Council Centre of Excellence Scheme (Project Number CE 140100012) and the AIIM Gold Grant.

\section{Acknowledgements}

Funding from the Australian Research Council Centre of Excellence Scheme (ACES, Project Number CE 140100012) is gratefully acknowledged. The authors would like to thank the Australian National Nanofabrication Facility-Materials node (ANFF) and the UOW Electron Microscopy Centre for equipment use. Y. C. acknowledges the support of CSC scholarship from the Ministry of Education of P. R. China.

\section{References}

(1) Cao, S.; Shi, L.; Miao, M.; Fang, J.; Zhao, H.; Feng, X. Solution-Processed Flexible PaperElectrode for Lithium-Ion Batteries Based on $\mathrm{MoS}_{2}$ Nanosheets Exfoliated with Cellulose Nanofibrils. Electrochim. Acta 2019, 22-30. https://doi.org/10.1016/j.electacta.2018.12.067.

(2) Jiao, Y.; Mukhopadhyay, A.; Ma, Y.; Yang, L.; Hafez, A. M.; Zhu, H. Ion Transport Nanotube Assembled with Vertically Aligned Metallic $\mathrm{MoS}_{2}$ for High Rate Lithium-Ion Batteries. Adv. Energy Mater. 2018, 8 (15), 1-9. https://doi.org/10.1002/aenm.201702779.

(3) Fang, X.; Hua, C.; Guo, X.; Hu, Y.; Wang, Z.; Gao, X.; Wu, F.; Wang, J.; Chen, L. Lithium Storage in Commercial $\mathrm{MoS}_{2}$ in Different Potential Ranges. Electrochim. Acta 2012, 81, $155-160$. 
(4) Yang, M.; Ko, S.; Im, J. S.; Choi, B. G. Free-Standing Molybdenum Disulfide/Graphene Composite Paper as a Binder- and Carbon-Free Anode for Lithium-Ion Batteries. J. Power Sources 2015, 288, 76-81. https://doi.org/10.1016/j.jpowsour.2015.04.063.

(5) Wang, C.; Wallace, G. G. Flexible Electrodes and Electrolytes for Energy Storage. Electrochim. Acta 2015, 175, 87-95. https://doi.org/10.1016/j.electacta.2015.04.067.

(6) Ge, Y.; Wang, C.; Zhao, Y.; Liu, Y.; Chao, Y.; Zheng, T.; Wallace, G. G. An Electrosynthesized 3D Porous Molybdenum Sulfide/Graphene Film with Enhanced Electrochemical Performance for Lithium Storage. Small 2018, 14 (9), 1-7. https://doi.org/10.1002/smll.201703096.

(7) Liu, Q.; Huo, J.; Ma, Z.; Wu, Z.; Wang, S. In-Situ Formation of $\mathrm{Ni}_{3} \mathrm{~S}_{2}$ Interlayer between $\mathrm{MoS}_{2}$ and Ni Foam for High-Rate and Highly-Durable Lithium Ion Batteries. Electrochim. Acta 2016, 206, 52-60. https://doi.org/10.1016/j.electacta.2016.04.121.

(8) Wang, J.; Liu, J.; Chao, D.; Yan, J.; Lin, J.; Shen, Z. X. Self-Assembly of Honeycomb-like $\mathrm{MoS}_{2}$ Nanoarchitectures Anchored into Graphene Foam for Enhanced Lithium-Ion Storage. Adv. Mater. 2014, 26 (42), 7162-7169. https://doi.org/10.1002/adma.201402728.

(9) Xie, D.; Tang, W. J.; Xia, X. H.; Wang, D. H.; Zhou, D.; Shi, F.; Wang, X. L.; Gu, C. D.; $\mathrm{Tu}$, J. P. Integrated 3D Porous $\mathrm{C}-\mathrm{MoS}_{2} /$ Nitrogen-Doped Graphene Electrode for High Capacity and Prolonged Stability Lithium Storage. J. Power Sources 2015, 296, 392-399. https://doi.org/10.1016/j.jpowsour.2015.07.074.

(10) David, L.; Bhandavat, R.; Singh, G. $\mathrm{MoS}_{2} /$ Graphene Composite Paper for Sodium-Ion Battery Electrodes. ACS Nano 2014, 8 (2), 1759-1770. https://doi.org/10.1021/nn406156b.

(11) Chao, Y.; Jalili, R.; Ge, Y.; Wang, C.; Zheng, T.; Shu, K.; Wallace, G. G. Self-Assembly of Flexible Free-Standing 3D Porous $\mathrm{MoS}_{2}$-Reduced Graphene Oxide Structure for HighPerformance Lithium-Ion Batteries. Adv. Funct. Mater. 2017, 27 (22), 1700234. https://doi.org/10.1002/adfm.201700234.

(12) Sun, H.; Mei, L.; Liang, J.; Zhao, Z.; Lee, C.; Fei, H.; Ding, M.; Lau, J.; Li, M.; Wang, C.; Xu, X.; Hao, G.; Papandrea, B.; Shakir, I.; Dunn, B.; Huang, Y.; Duan, X. Three- 
Dimensional Holey-Graphene/Niobia Composite Architectures for Ultrahigh-Rate Energy Storage. Science. 2017, 356 (6338), 599-604. https://doi.org/10.1126/science.aam5852.

(13) Wang, C.; Li, D.; Too, C. O.; Wallace, G. G. Electrochemical Properties of Graphene Paper Electrodes Used in Lithium Batteries. Chem. Mater. 2009, 21 (13), 2604-2606. https://doi.org/10.1021/cm900764n.

(14) Lee, W. S. V.; Peng, E.; Loh, T. A. J.; Huang, X.; Xue, J. M. Few-Layer MoS2-Anchored Graphene Aerogel Paper for Free-Standing Electrode Materials. Nanoscale 2016, 8 (15), 8042-8047. https://doi.org/10.1039/c6nr00340k.

(15) Kim, J. H.; Lee, S.; Lee, J. W.; Song, T.; Paik, U. 3D-Interconnected Nanoporous RGOCNT Structure for Supercapacitors Application. Electrochim. Acta 2014, 125, 536-542. https://doi.org/10.1016/J.ELECTACTA.2014.01.142.

(16) Tung, V. C.; Huang, J.-H.; Tevis, I.; Kim, F.; Kim, J.; Chu, C.-W.; Stupp, S. I.; Huang, J. Surfactant-Free Water-Processable Photoconductive All-Carbon Composite. J. Am. Chem. Soc 2011, 133, 4940-4947. https://doi.org/10.1021/ja1103734.

(17) Ge, Y.; Wang, C.; Shu, K.; Zhao, C.; Jia, X.; Gambhir, S.; Wallace, G. G. A Facile Approach for Fabrication of Mechanically Strong Graphene/Polypyrrole Films with Large Areal Capacitance for Supercapacitor Applications. RSC Adv. 2015, 5 (124), 102643-102651. https://doi.org/10.1039/c5ra21100j.

(18) Fu, K.; Wang, Y. Y.; Yan, C.; Yao, Y.; Chen, Y.; Dai, J.; Lacey, S.; Wang, Y. Y.; Wan, J.; Li, T.; Wang, Z.; Xu, Y.; Hu, L. Graphene Oxide-Based Electrode Inks for 3D-Printed Lithium-Ion Batteries. Adv. Mater. 2016, 28 (13), 2587-2594. https://doi.org/10.1002/adma.201505391.

(19) He, P.; Zhao, K.; Huang, B.; Zhang, B.; Huang, Q.; Chen, T.; Zhang, Q. Mechanically Robust and Size-Controlled $\mathrm{MoS}_{2} /$ Graphene Hybrid Aerogels as High-Performance Anodes for Lithium-Ion Batteries. J. Mater. Sci. 2018, 53 (6), 4482-4493. https://doi.org/10.1007/s10853-017-1853-4.

(20) Qi, X.; Xue, Z.; Du, K.; Xie, Y.; Cao, Y.; Li, W.; Peng, Z.; Hu, G. Graphene-Analogous 
Structural $\mathrm{MoS}_{2}$ Modification to Improve Electrochemical Properties of Ni-Rich Layered Oxide Cathode Material for Lithium-Ion Batteries. J. Power Sources 2018, 397, 288-295. https://doi.org/10.1016/J.JPOWSOUR.2018.07.037.

(21) Jalili, R.; Aboutalebi, S. H.; Esrafilzadeh, D.; Konstantinov, K.; Moulton, S. E.; Razal, J. M.; Wallace, G. G. Organic Solvent-Based Graphene Oxide Liquid Crystals: A Facile Route toward the Next Generation. ACS Nano 2013, No. 5, At press.

(22) Choi, J.; Kim, J.; Wagner, P.; Gambhir, S.; Jalili, R.; Byun, S.; Sayyar, S.; Lee, Y. M.; Macfarlane, D. R.; Wallace, G. G.; Officer, D. L. Energy Efficient Electrochemical Reduction of CO 2 to CO Using a Three-Dimensional Porphyrin/ Graphene Hydrogel. Energy Environ. Sci 2019, 12, 747. https://doi.org/10.1039/c8ee03403f.

(23) Chidembo, A. T.; Aboutalebi, S. H.; Konstantinov, K.; Wexler, D.; Liu, H. K.; Dou, S. X. Liquid Crystalline Dispersions of Graphene-Oxide-Based Hybrids: A Practical Approach towards the next Generation of 3D Isotropic Architectures for Energy Storage Applications. Part. Part. Syst. Charact. 2014, 31 (4), 465-473. https://doi.org/10.1002/ppsc.201300254.

(24) Islam, M. M.; Chidembo, A. T.; Aboutalebi, S. H.; Cardillo, D.; Liu, H. K.; Konstantinov, K.; Dou, S. X. Liquid Crystalline Graphene Oxide/PEDOT:PSS Self-Assembled 3D Architecture for Binder-Free Supercapacitor Electrodes. Front. Energy Res. 2014, 2 (August), 1-11. https://doi.org/10.3389/fenrg.2014.00031.

(25) Compton, O. C.; Nguyen, S. B. T. Graphene Oxide, Highly Reduced Graphene Oxide, and Graphene: Versatile Building Blocks for Carbon-Based Materials. Small 2009, 6 (6), $711-$ 723. https://doi.org/10.1002/smll.200901934.

(26) Aboutalebi, S. H.; Gudarzi, M. M.; Zheng, Q. Bin; Kim, J. K. Spontaneous Formation of Liquid Crystals in Ultralarge Graphene Oxide Dispersions. Adv. Funct. Mater. 2011, 21 (15), 2978-2988. https://doi.org/10.1002/adfm.201100448.

(27) Poulin, P.; Divoux, T.; Zakri, C.; Aboutalebi, S. H.; Jalili, R.; Colin, A.; Neri, W.; Nallet, F.; Wallace, G. Superflexibility of Graphene Oxide. Proc. Natl. Acad. Sci. 2016, 113 (40), 11088-11093. https://doi.org/10.1073/pnas.1605121113. 
(28) Natarajan, C.; Fujimoto, H.; Mabuchi, A.; Tokumitsu, K.; Kasuh, T. Effect of Mechanical Milling of Graphite Powder on Lithium Intercalation Properties. J. Power Sources 2001, 92 (1-2), 187-192. https://doi.org/10.1016/S0378-7753(00)00528-0.

(29) Jalili, R.; Aboutalebi, S. H.; Esrafilzadeh, D.; Shepherd, R. L.; Chen, J.; AminorroayaYamini, S.; Konstantinov, K.; Minett, A. I.; Razal, J. M.; Wallace, G. G. Scalable One-Step Wet-Spinning of Graphene Fibers and Yarns from Liquid Crystalline Dispersions of Graphene Oxide: Towards Multifunctional Textiles. Adv. Funct. Mater. 2013, 23 (43), 5345-5354. https://doi.org/10.1002/adfm.201300765.

(30) Aboutalebi, S. H.; Chidembo, A. T.; Salari, M.; Konstantinov, K.; Wexler, D.; Liu, H. K.; Dou, S. X. Comparison of GO, GO/MWCNTs Composite and MWCNTs as Potential Electrode Materials for Supercapacitors. https://doi.org/10.1039/c1ee01039e.

(31) Jalili, R.; Aboutalebi, S. H.; Esrafilzadeh, D.; Konstantinov, K.; Razal, J. M.; Moulton, S. E.; Wallace, G. G. Formation and Processability of Liquid Crystalline Dispersions of Graphene Oxide. Mater. Horizons 2014, 1 (1), 87-91. https://doi.org/10.1039/c3mh00050h.

(32) Chao, Y.; Jalili, R.; Ge, Y.; Wang, C.; Zheng, T.; Shu, K.; Wallace, G. G. Self-Assembly of Flexible Free-Standing 3D Porous $\mathrm{MoS}_{2}$-Reduced Graphene Oxide Structure for HighPerformance Lithium-Ion Batteries. Adv. Funct. Mater. 2017, 27 (22), 1700234.

(33) Liu, Y.; Zhao, Y.; Jiao, L.; Chen, J. A Graphene-like $\mathrm{MoS}_{2} /$ Graphene Nanocomposite as a Highperformance Anode for Lithium Ion Batteries. J. Mater. Chem. A 2014, 2 (32), 1310913115. https://doi.org/10.1039/c4ta01644k.

(34) Chen, B.; Zhao, N.; Guo, L.; He, F.; Shi, C.; He, C.; Li, J.; Liu, E. Facile Synthesis of 3D Few-Layered $\mathrm{MoS}_{2}$ Coated $\mathrm{TiO}_{2}$ Nanosheet Core-Shell Nanostructures for Stable and HighPerformance Lithium-Ion Batteries. Nanoscale 2015, 7 (30), 12895-12905. https://doi.org/10.1039/c5nr03334a.

(35) Shi, Z. T.; Kang, W.; Xu, J.; Sun, Y. W.; Jiang, M.; Ng, T. W.; Xue, H. T.; Yu, D. Y. W.; Zhang, W.; Lee, C. S. Hierarchical Nanotubes Assembled from $\mathrm{MoS}_{2}$-Carbon Monolayer Sandwiched Superstructure Nanosheets for High-Performance Sodium Ion Batteries. Nano Energy 2016, 22, 27-37. https://doi.org/10.1016/j.nanoen.2016.02.009. 
(36) Huang, K. J.; Wang, L.; Liu, Y. J.; Liu, Y. M.; Wang, H. B.; Gan, T.; Wang, L. L. Layered $\mathrm{MoS}_{2}$-Graphene Composites for Supercapacitor Applications with Enhanced Capacitive Performance. Int. J. Hydrogen Energy 2013, 38 (32), 14027-14034. https://doi.org/10.1016/j.ijhydene.2013.08.112.

(37) Ricciardulli, A. G.; Yang, S.; Wetzelaer, G.-J. A. H.; Feng, X.; Blom, P. W. M. Hybrid Silver Nanowire and Graphene-Based Solution-Processed Transparent Electrode for Organic Optoelectronics. Adv. Funct. Mater. 2018, 28 (14), 1706010. https://doi.org/10.1002/adfm.201706010.

(38) Lin, M.-C.; Gong, M.; Lu, B.; Wu, Y.; Wang, D.-Y.; Guan, M.; Angell, M.; Chen, C.; Yang, J.; Hwang, B.-J.; Dai, H. An Ultrafast Rechargeable Aluminium-Ion Battery. Nature 2015, 520 (7547), 324-328. https://doi.org/10.1038/nature14340.

(39) Thangappan, R.; Kalaiselvam, S.; Elayaperumal, A.; Jayavel, R.; Arivanandhan, M.; Karthikeyan, R.; Hayakawa, Y. Graphene Decorated with $\mathrm{MoS}_{2}$ Nanosheets: A Synergetic Energy Storage Composite Electrode for Supercapacitor Applications. Dalt. Trans. 2016, 45 (6), 2637-2646. https://doi.org/10.1039/C5DT04832J.

(40) Liu, S.; Peng, W.; Sun, H.; Wang, S. Physical and Chemical Activation of Reduced Graphene Oxide for Enhanced Adsorption and Catalytic Oxidation. Nanoscale 2014, 6 (2), 766-771. https://doi.org/10.1039/C3NR04282K.

(41) Li, H.; Su, Q.; Kang, J.; Feng, H.; Huang, P.; Huang, M.; Feng, M.; Tu, G.; Du, G. MoS2 Nanosheets Attached on Carbon Microspheres Used as Anodes for Lithium Ion Batteries. Ceram. Int. 2018, 44 (5), 5311-5318. https://doi.org/10.1016/J.CERAMINT.2017.12.148.

(42) Huang, G.; Chen, T.; Chen, W.; Wang, Z.; Chang, K.; Ma, L.; Huang, F.; Chen, D.; Lee, J. Y. Graphene-like $\mathrm{MoS}_{2} /$ Graphene Composites: Cationic Surfactant-Assisted Hydrothermal Synthesis and Electrochemical Reversible Storage of Lithium. Small 2013, 9 (21), 36933703. https://doi.org/10.1002/smll.201300415.

(43) Hwang, H.; Kim, H.; Cho, J. $\mathrm{MoS}_{2}$ Nanoplates Consisting of Disordered Graphene-like Layers for High Rate Lithium Battery Anode Materials. Nano Lett 2011, 11, 4826-4830. https://doi.org/10.1021/n1202675f. 
(44) Hu, Z.; Liu, Q.; Sun, W.; Li, W.; Tao, Z.; Chou, S. L.; Chen, J.; Dou, S. X. MoS2 with an Intercalation Reaction as a Long-Life Anode Material for Lithium Ion Batteries. Inorg. Chem. Front. 2016, 3 (4), 532-535. https://doi.org/10.1039/c5qi00237k.

(45) Wang, X.; Li, G.; Seo, M. H.; Hassan, F. M.; Hoque, M. A.; Chen, Z. Sulfur Atoms Bridging Few-Layered $\mathrm{MoS}_{2}$ with S-Doped Graphene Enable Highly Robust Anode for Lithium-Ion $\begin{array}{llllll}\text { Batteries. } \quad \text { Adv. } & \text { Energy } & \text { 2015, } & 5 & \text { (23), } & 1501106 .\end{array}$ https://doi.org/10.1002/aenm.201501106.

(46) Xiao, J.; Liu, G.; Liu, J.; Lemmon, J. P.; Koech, P. K.; Xun, S.; Yang, X.-Q.; Wang, X. Electrochemically Induced High Capacity Displacement Reaction of PEO/ $\mathrm{MoS}_{2} /$ Graphene Nanocomposites with Lithium. Adv. Funct. Mater. 2011, 21 (15), 2840-2846. https://doi.org/10.1002/adfm.201002752.

(47) Guo, P.; Sun, K.; Liu, D.; Cheng, P.; Lv, M.; Liu, Q.; He, D. Molybdenum Disulfide Nanosheets Embedded in Hollow Nitrogen-Doped Carbon Spheres for Efficient Lithium/Sodium Storage with Enhanced Electrochemical Kinetics. Electrochim. Acta 2018, 283, 646-654. https://doi.org/10.1016/j.electacta.2018.06.141.

(48) Zhu, Q.; Zhao, C.; Bian, Y.; Mao, C.; Peng, H.; Li, G.; Chen, K. MoS 2 /Nitrogen-Doped Carbon Hybrid Nanorods with Expanded Interlayer Spacing as an Advanced Anode Material for Lithium Ion Batteries. Synth. Met. 2018, 235 (December 2017), 103-109. https://doi.org/10.1016/j.synthmet.2017.11.009.

(49) Chen, C.; Xie, X.; Anasori, B.; Sarycheva, A.; Makaryan, T.; Zhao, M.; Urbankowski, P.; Miao, L.; Jiang, J.; Gogotsi, Y. $\mathrm{MoS}_{2}$-on-MXene Heterostructures as Highly Reversible Anode Materials for Lithium-Ion Batteries. Angew. Chemie - Int. Ed. 2018, 57 (7), 18461850. https://doi.org/10.1002/anie.201710616.

(50) Shan, T. T.; Xin, S.; You, Y.; Cong, H. P.; Yu, S. H.; Manthiram, A. Combining NitrogenDoped Graphene Sheets and $\mathrm{MoS}_{2}$ : A Unique Film-Foam-Film Structure for Enhanced Lithium Storage. Angew. Chemie - Int. Ed. 2016, 55 (41), 12783-12788. https://doi.org/10.1002/anie.201606870.

(51) Wang, G.; Zhang, J.; Yang, S.; Wang, F.; Zhuang, X.; Müllen, K.; Feng, X. Vertically 
Aligned $\mathrm{MoS}_{2}$ Nanosheets Patterned on Electrochemically Exfoliated Graphene for HighPerformance Lithium and Sodium Storage. Adv. Energy Mater. 2018, 8 (8), 1702254. https://doi.org/10.1002/aenm.201702254.

(52) Wang, B.; Ryu, J.; Choi, S.; Song, G.; Hong, D.; Hwang, C.; Chen, X.; Wang, B.; Li, W.; Song, H.-K.; Park, S.; Ruoff, R. S. Folding Graphene Film Yields High Areal Energy Storage in Lithium-Ion Batteries. ACS Nano 2018, 12 (2), 1739-1746. https://doi.org/10.1021/acsnano.7b08489.

(53) Dubarry, M.; Liaw, B. Y.; Chen, M. S.; Chyan, S. S.; Han, K. C.; Sie, W. T.; Wu, S. H. Identifying Battery Aging Mechanisms in Large Format Li Ion Cells. J. Power Sources 2011, 196 (7), 3420-3425. https://doi.org/10.1016/j.jpowsour.2010.07.029.

(54) Li, Y.; Wang, H.; Xie, L.; Liang, Y.; Hong, G.; Dai, H. MoS 2 Nanoparticles Grown on Graphene: An Advanced Catalyst for the Hydrogen Evolution Reaction. J. Am. Chem. Soc. 2011, 133 (19), 7296-7299. https://doi.org/10.1021/ja201269b.

For Table of Contents Only

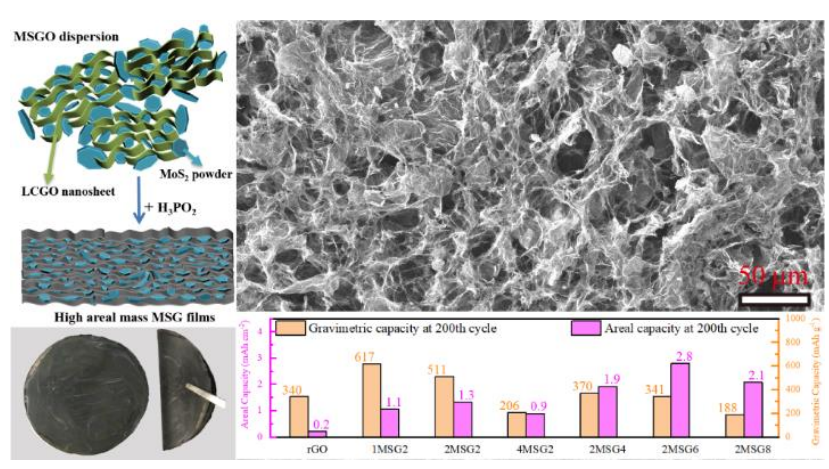


